Supporting Information

\title{
Double Hangman Iron Porphyrin and the Effect of Electrostatic Nonbonding Interactions on Carbon Dioxide Reduction
}

\author{
Charles G. Margarit, Naomi G. Asimow, Miguel I. Gonzalez, and Daniel G. Nocera * \\ Department of Chemistry and Chemical Biology, Harvard University, 12 Oxford Street, Cambridge, MA 02138 \\ Email: dnocera@fas.harvard.edu
}




\section{Table of Contents}

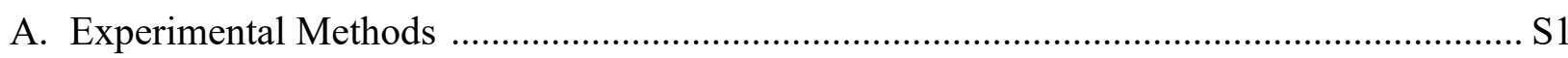

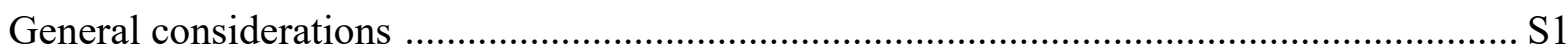

Synthesis of dibenzofuran-modified porphyrins .......................................................... S 1

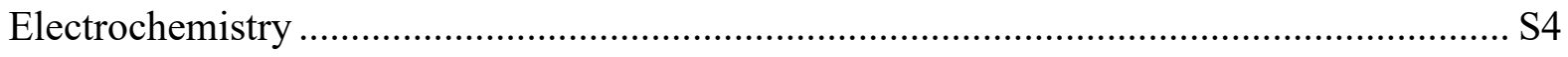

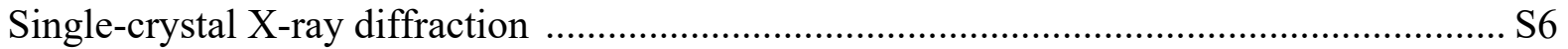

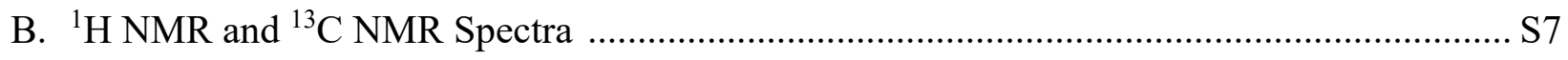

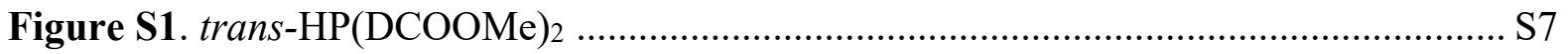

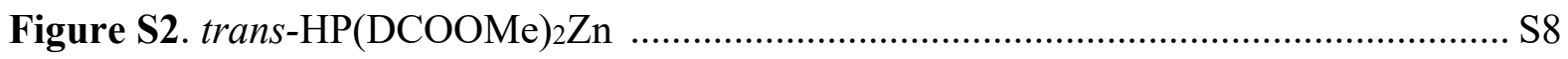

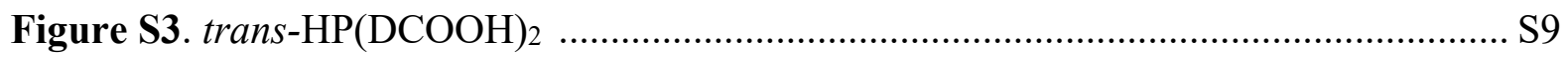

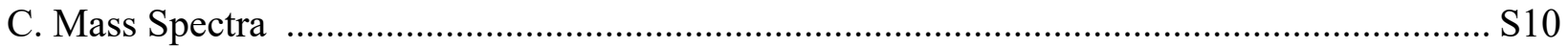

Figure S4. trans-HP(DCOOMe $)_{2}$ and trans-HP(DCOOMe $)_{2} \mathrm{Zn}$.................................... S10

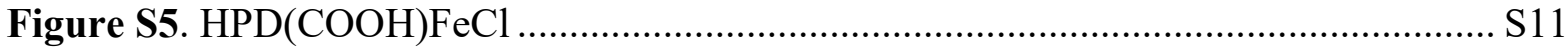

Figure S6. trans-HP(DCOOH $)_{2}$ and (bottom) trans- $\mathrm{HP}(\mathrm{DCOOH})_{2} \mathrm{FeCl}$........................ S12

C. Figure S7. UV-vis Spectra of Porphyrin Compounds ................................................. S13

D. Figure S8. Atomic Displacement Parameters for trans-HP(DCOOH) $2 \mathrm{Zn} \quad$........................ S14

E. Table S1. Crystallographic Data of trans-HP(DCOOH) $2 \mathrm{Zn}$.......................................... S15

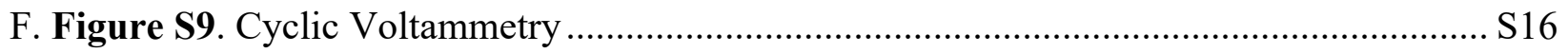

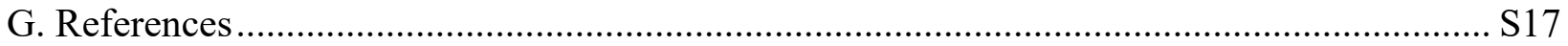




\section{A. Experimental Methods}

General considerations. ${ }^{1} \mathrm{H}$ NMR spectra were recorded at ambient temperature on a JEOL ECZ400S $400 \mathrm{MHz}$ spectrometer. All spectra were referenced to trace protonated DMSO (2.50 $\mathrm{ppm})$ with water $(3.33 \mathrm{ppm})$ as an internal standard (measured values for $\delta$ are given in parts per million (ppm)). Electrospray ionization mass spectra (ESI-MS) were obtained using a Bruker micrOTOF-QII. Absorption spectral measurements were made for each porphyrin using a Cary 5000 UV-vis-nIR spectrometer from Varian employing the software Cary WinUV. Quartz cells with a $10 \mathrm{~mm}$ path length were used. The microwave-assisted reactions were performed inside the cavity of a CEM Discover microwave synthesis system equipped with infrared, pressure, and temperature sensors for monitoring the synthesis. The reaction vessels were $35 \mathrm{~mL}$ crimp-sealed thick-wall glass tubes. The contents of each vessel were stirred with a magnetic stirrer. Automated chromatography was performed on all dibenzofuran-substituted compounds before porphyrin formation and on all metallated porphyrins using a Biotage Isolera One equipped with a UV-vis spectrometer and auto fractionation arm.

$N, N$-dimethylformamide (DMF) was purchased from Sigma Aldrich and purified by passage through alumina and stored over activated $3 \AA$ sieves under a nitrogen atmosphere for at least 24 $\mathrm{h}$ before use. Tetrabutylammonium hexafluorophosphate $\left(\left[\mathrm{TBA}^{+}\right]\left[\mathrm{PF}_{6}{ }^{-}\right]\right)$was purchased from Sigma Aldrich and was recrystallized from ethanol twice before being dried in vacuo at $70^{\circ} \mathrm{C}$ and stored under nitrogen atmosphere inside a glovebox.

Tetrahydrofuran (THF) was purified by passage through alumina for use in air free reactions. The following chemicals were used as received: acetonitrile $(\mathrm{MeCN})$, ethyl acetate (EtOAc), dichloromethane $(\mathrm{DCM})$, phenol $(\mathrm{PhOH})$, sodium chloride $(\mathrm{NaCl})$, sodium bicarbonate $\left(\mathrm{NaHCO}_{3}\right)$, 2,3-dichloro-5,6-dicyano-1,4-benzoquinone (DDQ), pyrrole, 3,4,5-trimethoxybenzaldehyde, iron(II) bromide $\left(\mathrm{FeBr}_{2}\right)$, tetraethylammonium acetate tetrahydrate $\left(\left[\mathrm{TEA}^{+}\right]\left[\mathrm{OAc}^{-}\right.\right.$ ]), and triethylamine ( $\mathrm{NEt}_{3}$ ) from Sigma Aldrich; dimethylsulfoxide- $\mathrm{d}_{6}$ (DMSO- $\mathrm{d}_{6}$ ) from Cambridge Isotope Laboratories; trifluoroacetic acid from Oakwood Chemicals.

Synthesis of dibenzofuran-modified porphyrins. The trimethoxyphenyl substituent was chosen for the non-dibenzofuran modified meso-positions of the porphyrin macrocycle for ease of synthesis. Fe metallation of hangman porphyrins was accomplished in moderate yields using microwave assisted synthesis in acetonitrile with $\mathrm{Fe}(\mathrm{OAc}) 2$. The isolation of all known compounds was confirmed by NMR spectroscopy and mass spectrometry and compared to published values. In the cases of newly synthesized HP(DCOOMe)2, HP(DCOOMe)2Zn, HP(DCOOH $)_{2}$, original ${ }^{1} \mathrm{H}$ - and ${ }^{13} \mathrm{C}-\mathrm{NMR}$ were recorded. Mass spectrometry and UV-vis spectra and were recorded for $\mathrm{HPD}(\mathrm{COOH}), \mathrm{HP}(\mathrm{DCOOH})_{2}, \mathrm{HPD}(\mathrm{COOH}) \mathrm{FeCl}$, and $\mathrm{HP}(\mathrm{DCOOH})_{2} \mathrm{FeCl}$. Detailed synthetic conditions and characterizations of the Fe hangman porphyrins are provided below.

The compounds 5-(3,4,5-trimethoxyphenyl) dipyrro methane (3,4,5-DPM), ${ }^{1}$ methyl-6-formyl-4dibenzo furan methyl ester (DBF), ${ }^{2}$ 5-(4-(dibenzofuran-6-carboxylic acid))-10,15,20-tri(3,4,5trimethoxyphenyl)porphyrin $(\mathrm{HPD}(\mathrm{COOH})),{ }^{2}$ and tetrakis $(3,4,5$-trimethoxyphenyl) porphyrinato iron(III) chloride $\left(\mathrm{A}_{4}(\mathrm{OMe}){ }_{3} \mathrm{FeCl}\right)^{3}$ were synthesized according to literature procedures in good yield. 
5-(4-(Dibenzofuran-6-carboxlyic acid))-10,15,20-tris(3,4,5-trimethoxyphenyl) porphyrin iron(II) chloride (HPD(COOH)FeCl). HPD(COOH) (31 mg, $29.1 \mu \mathrm{mol})$ was dissolved in $5 \mathrm{~mL}$ of DMF and added to a $10 \mathrm{~mL}$ CEM microwave tube. To this solution was added 20 equiv of $\mathrm{Fe}(\mathrm{OAc})_{2}$. The tube and its contents were microwaved at $75^{\circ} \mathrm{C}$ for $1.5 \mathrm{~h}$ with stirring and constant cooling applied. When the reaction finished, the contents of the tube were added to a separatory funnel containing $100 \mathrm{~mL}$ of EtOAc and was washed twice with $20 \% \mathrm{HCl}$ (aq), once with $\mathrm{DI} \mathrm{H}_{2} \mathrm{O}$, and once with brine. The organic layer was separated before being filtered through a filter paper funnel containing $20 \mathrm{~g}$ of $\mathrm{Na}_{2} \mathrm{SO}_{4}$ and dried via rotary evaporation. The crude product was then taken up in minimal DCM and purified by column chromatography on the Biotage Isolera One using a 10 g SNAP Ultra column containing $25 \mu \mathrm{m}$ monodispersed silica (100\% DCM for 1 column volume followed by a 10 -column volume gradient to $15 \% \mathrm{MeOH}$ in $\mathrm{DCM}$ ). The lone peak detected by absorbance at $420 \mathrm{~nm}$ visible light absorbance was then treated with $10 \mathrm{~mL}$ of $20 \%$ $\mathrm{HCl}(\mathrm{aq})$ and stirred for $1 \mathrm{~h}$ before adding to a separatory funnel where the organic layer was separated off and filtered through a filter paper funnel containing $20 \mathrm{~g}$ of $\mathrm{Na}_{2} \mathrm{SO}_{4}$ and dried via rotary evaporation to yield the final product. Yield $25 \mathrm{mg}(80 \%)$. UV-vis (DMF): $\lambda_{\max }, \mathrm{nm} 422$, 505, 576. MS(ESI): $m / z 1072.2593$ (Calcd. for $[\mathrm{M}-\mathrm{Cl}]^{+}$1072.2613).

5-(3,4,5-Trimethoxyphenyl)dipyrromethane (3,4,5-DPM). Pyrrole (50 equiv, $100 \mathrm{~mL}, 1.441 \mathrm{~mol})$ was added to a $250 \mathrm{~mL}$ round bottom flask containing a stir bar. The reagent was degassed using argon through a fritted glass rod for $15 \mathrm{~min}$ before adding 3,4,5-trimethoxybenzaldehyde (1 equiv, $5.655 \mathrm{~g}, 28.82 \mathrm{mmol}$ ) and capping the flask with a rubber septum. 3,4,5-trimethoxybenzaldehyde was added against a nitrogen stream and allowed to dissolve fully before adding in trifluoroacetic acid $(0.1$ equiv, $221 \mu \mathrm{L}, 2.88 \mathrm{mmol})$ dropwise. The reaction was stirred for $2 \mathrm{~h}$ and then quenched with triethylamine $(0.1$ equiv, $410 \mu \mathrm{L}, 2.88 \mathrm{mmol})$ and stirred for an additional hour. At this point, the reaction mixture was diluted with $100 \mathrm{~mL}$ of toluene, transferred to a $500 \mathrm{~mL}$ round bottom flask and rotary evaporated to remove as much pyrrole as possible. This trituration was repeated two more times with $100 \mathrm{~mL}$ of toluene each time to finally yield a flocculent solid on the walls of the flask. The solid was then dissolved in a minimal amount of hot $80 \% \mathrm{EtOH}$ (aq) and set aside to crystallize. Dark yellow crystals were collected by filtration and washing with hexanes before being recrystallized using the same procedure. Finally, mustard yellow crystals were collected by filtration, washed with hexanes, and dried under vacuum to yield 5-(3,4,5-triemthoxyphenyl)dipyrromethane. Yield $6.715 \mathrm{~g}(75 \%)$.

5a,15ß-bis(4-(dibenzofuran-6-methylester))-10,20-bis(3,4,5-trimethoxy-phenyl) porphyrin (trans-HP(DCOOMe $\left.)_{2}\right)$. A $500 \mathrm{~mL}$ round bottom flask was flame dried under evacuation to remove trace water before adding $500 \mathrm{~mL}$ of DCM. The solvent was degassed with Ar using a fritted glass rod for $15 \mathrm{~min}$ to drive out any dissolved $\mathrm{O}_{2}$. The reaction flask was charged with 3,4,5-DPM (2 equiv, $775 \mathrm{mg}, 2.5 \mathrm{mmol}, 5 \mathrm{mM}$ ) and DBF (2 equiv, $635 \mathrm{mg}, 2.5 \mathrm{mmol}, 5 \mathrm{mM}$ ), capped under a nitrogen atmosphere using a rubber septum, and stirred for 10 min or until all solids had dissolved. TFA ( $8 \mathrm{eq}, 765 \mu \mathrm{L}, 10 \mathrm{mmol}$ ) was added dropwise to the reaction through the septum using a syringe and needle and the reaction was stirred for $15 \mathrm{~min}$ under nitrogen atmosphere. The crude mixture was quenched with solid DDQ (4 equiv, $555 \mathrm{mg}, 2.5 \mathrm{mmol}$ ) added all at once to the flask and stirred for $15 \mathrm{~min}$ before adding NEt 3 (8 equiv, $1.42 \mathrm{~mL}, 10 \mathrm{mmol}$ ) to neutralize the TFA catalyst. The entire reaction mixture was split into two $250 \mathrm{~mL}$ portions and 
dried via rotary evaporation. Then the crude mixture was taken up in $100 \mathrm{~mL}$ of DCM and had 20 $\mathrm{g}$ of $25 \mu \mathrm{M}$ monodispersed silica added before being dried via rotary evaporation. The dry-loaded reaction mixture was added to a $70 \mathrm{~g}$ auxiliary dry loading tube supplied by Biotage and purified by column chromatography through a $100 \mathrm{~g}$ SNAP Ultra column containing $25 \mu \mathrm{m}$ monodispersed silica (1 column volume of $100 \%$ DCM, 10 column volume gradient from $100 \%$ DCM to $35 \%$ EtOAc in DCM). The product eluted as the second major band as detected by absorbance at 420 $\mathrm{nm}$ Visible light absorbance on the column as an inseparable mixture of the $\alpha, \alpha$ - and $\alpha, \beta$-isomers. Isolation of the desired $\alpha, \beta$-isomer was achieved via overnight crystallization using minimal DCM layered with $4 \times$ volume of $\mathrm{MeOH}$ to offer a yield of $15 \%$ percent for the desired isomer. NMR spectroscopy confirmed that the preferred isomer was obtained. Yield $205 \mathrm{mg}(15 \%)$, UV-vis (DMF): $\lambda_{\max }, \mathrm{nm} 420,514,548,591,650 .{ }^{1} \mathrm{H}$ NMR (400 MHz; DMSO-d 6 ): $\delta 8.96$ (brd, 4H), 8.80 (brs, $4 \mathrm{H}), 8.72(\mathrm{~d}, 4 \mathrm{H}), 8.35(\mathrm{t}, 2 \mathrm{H}), 7.95(\mathrm{~d}, 4 \mathrm{H}), 7.58(\mathrm{~m}, 6 \mathrm{H}), 3.95(\mathrm{~s}, 6 \mathrm{H}), 3.87$ (t, $12 \mathrm{H}), 3.06$ $(\mathrm{d}, 6 \mathrm{H}),-2.72$ (s, $2 \mathrm{H}) .{ }^{13} \mathrm{C}$ NMR (101 MHz; DMSO-d6): $\delta$ 156.89, 154.93, 151.71, 137.96, 137.07, $129.66,127.37,126.27,126.17,123.88,123.46,122.58,113.35,107.51,97.70,67.14,66.22$, $62.98,60.89,56.67,51.95,40.68,40.47,40.27,40.06,39.85,39.64,39.43,33.69,29.42,24.09$, 23.82. MS(ESI): $m / z 1091.3481$ (Calcd. for $[\mathrm{M}+\mathrm{H}]^{+}$1091.3498).

5a,15ß-bis(4-(dibenzofuran-6-methylester))-10,20-bis(3,4,5-trimethoxy-phenyl) porphyrin (trans-HP(DCOOMe $\left.)_{2} Z \mathbf{Z n}\right)$. Trans-HP(DCOOMe) $)_{2}(100 \mathrm{mg}, 91.7 \mu \mathrm{mol})$ was taken up in $100 \mathrm{~mL}$ of $\mathrm{CHCl}_{3}$ in a $150 \mathrm{~mL}$ round bottom flask. To this was added $20 \mathrm{~mL}$ of MeOH containing 20 equiv of $\mathrm{Zn}(\mathrm{OAc})_{2} \cdot\left(\mathrm{H}_{2} \mathrm{O}\right)_{2}(336 \mathrm{mg}, 1.84 \mathrm{mmol})$ and the reaction was fitted with a reflux condenser and heated to $70{ }^{\circ} \mathrm{C}$ for $1 \mathrm{~h}$ The reaction was removed from the heat to cool down to room temperature and contents of the reaction were poured into a separatory funnel. The organic layer was subsequently washed with deionized water $(2 \times 100 \mathrm{~mL})$, and brine $(1 \times 100 \mathrm{~mL})$ before being filtered through a filter paper funnel containing $20 \mathrm{~g}$ of $\mathrm{Na}_{2} \mathrm{SO}_{4}$ and dried via rotary evaporation. The crude product was then taken up in minimal DCM and purified by column chromatography on the Biotage Isolera One using a $25 \mathrm{~g}$ SNAP Ultra column containing $25 \mu \mathrm{m}$ monodispersed silica (100\% DCM for 1 column volume followed by a 10 -column volume gradient to $35 \%$ EtOAc in DCM). The lone peak detected by absorbance at $420 \mathrm{~nm}$ visible light absorbance was collected and rotary evaporated to dryness, taken up in minimal DCM, layered with $4 \times$ volume of $\mathrm{MeOH}$ and set aside to crystallize overnight in $50 \%$ overall yield. Hot pink crystals were collected the next day and characterized by single-crystal $X$-ray diffraction which unambiguously identified the crystals as the $\alpha, \beta$-isomer. Yield $53.0 \mathrm{mg}$ (50\%), UV-vis (DMF) $\lambda$ max, $\mathrm{nm} 406,427,556,597 .{ }^{1} \mathrm{H}$ NMR (400 MHz: DMSO-d6): $\delta 8.90(\mathrm{~d}, 4 \mathrm{H}), 8.70(\mathrm{~m}, 8 \mathrm{H}), 8.27(\mathrm{t}, 2 \mathrm{H}), 7.92(\mathrm{~m}, 4 \mathrm{H}), 7.60(\mathrm{td}, \mathrm{J}$ = 7.9, 7.8, 2.2 Hz, 2H), $7.50(\mathrm{~m}, 4 \mathrm{H}), 3.96(\mathrm{~s}, 6 \mathrm{H}), 3.88(\mathrm{~d}, \mathrm{~J}=4.1 \mathrm{~Hz}, 12 \mathrm{H}), 3.13(\mathrm{~d}, \mathrm{~J}=4.8 \mathrm{~Hz}$, $6 \mathrm{H}) .{ }^{13} \mathrm{C}-\mathrm{NMR}(101 \mathrm{MHz}$; DMSO-d 6$): \delta 163.95,157.05,155.00,151.41,150.09,149.97,138.72$, $138.71,137.63,137.61,134.79,132.68,131.93,129.48,127.83,127.82,127.32,126.44,123.75$, $123.11,122.79,121.92,121.04,115.32,114.09,113.28,60.91,56.63,51.98,40.69,40.48,40.27$, 40.18, 40.06, 39.97, 39.85, 39.75, 39.64, 39.43, 39.30. MS(ESI): $m / z 1153.2665$ (Calcd. for $[\mathrm{M}+\mathrm{H}]^{+}$1153.2637).

5a,15ß-(4-(dibenzofuran-6-carboxylic acid))-10,20-bis(3,4,5-trimethoxy-phenyl) porphyrin (trans-HP(DCOOH$\left.)_{2}\right)$. Trans-HP(DCOOMe $)_{2}(50.0 \mathrm{mg}, 45.9 \mu \mathrm{mol})$ was taken up in $10 \mathrm{~mL}$ of THF and transferred to a $35 \mathrm{~mL}$ microwave tube containing $5 \mathrm{~mL}$ of $6 \mathrm{M} \mathrm{NaOH}$ (aq). The tube 
was capped and irradiated to $75{ }^{\circ} \mathrm{C}$ for $1.5 \mathrm{~h}$ with vigorous stirring to ensure a singular reaction phase was achieved throughout the duration of the reaction. The contents of the tube were poured into a separatory funnel containing $100 \mathrm{~mL}$ of EtOAc and the aqueous layer was removed. The organic layer was subsequently washed with $20 \% \mathrm{HCl}(\mathrm{aq})(2 \times 100 \mathrm{~mL})$, deionized water $(1 \times$ $100 \mathrm{~mL})$, and brine $(1 \times 100 \mathrm{~mL})$ before being filtered through a filter paper funnel containing 20 $\mathrm{g}$ of $\mathrm{Na}_{2} \mathrm{SO}_{4}$ and dried via rotary evaporation. The crude product was then taken up in minimal DCM and purified by column chromatography on the Biotage Isolera One using a $10 \mathrm{~g}$ SNAP Ultra column containing $25 \mu \mathrm{m}$ monodispersed silica (100\% DCM for 1 column volume followed by a 10 -column volume gradient to $35 \% \mathrm{MeOH}$ in $\mathrm{DCM})$. The lone peak detected by absorbance at $420 \mathrm{~nm}$ Visible light absorbance was rotary evaporated to dryness, taken up in minimal DCM and precipitated with pentane $(4 \times$ volume of DCM) and spun down to collect solids. The supernatant was discarded, fresh pentane added, and the solids centrifuged and collected before being pumped to dryness under evacuation. The solid was then taken up in minimal THF and layered with heptane ( $4 \times$ volume of DCM) and set aside over night to crystallize in $40 \%$ yield. The crystals were collected and rinsed with pentane to remove residual polar and high boiling point solvents. Though the crystals did not diffract well enough to collect a structure, NMR spectroscopy confirmed the porphyrin in the desired $\alpha, \beta$-isomerization state. Yield $19.5 \mathrm{mg}(40 \%)$, UV-vis (DMF): $\lambda_{\max }, \mathrm{nm} 422,515,550,592,648 .{ }^{1} \mathrm{H}$ NMR (400 MHz; DMSO-d6): $\delta 12.37$ (s, 2H), 8.95 $(\mathrm{d}, 4 \mathrm{H}), 8.73(\mathrm{~m}, 8 \mathrm{H}), 8.29(\mathrm{~d}, \mathrm{~J}=6.5 \mathrm{~Hz}, 2 \mathrm{H}), 7.92(\mathrm{t}, 4 \mathrm{H}), 7.59(\mathrm{~m}, 6 \mathrm{H}), 3.95(\mathrm{~s}, 6 \mathrm{H}), 3.87(\mathrm{~s}$, $12 \mathrm{H}),-2.76(\mathrm{~s}, 2 \mathrm{H})) .{ }^{13} \mathrm{C}$ NMR (101 MHz: DMSO-d6): $\delta 208.38,165.29,156.91,155.03,153.13$, 151.72, 138.01, 136.99, 134.44, 131.87, 130.14, 126.71, 126.16, 126.07, 123.77, 123.21, 113.94, $113.44,68.79,60.89,56.74,40.06,27.94,22.27$. MS (ESI): $m / z 1063.3198\left(\right.$ Calcd. for $[\mathrm{M}+\mathrm{H}]^{+}$ 1063.3185).

5a,15ß-bis(4-(Dibenzofuran-6-carboxylic acid))-10,20-bis(3,4,5-trimethoxy-phenyl) porphyrin iron(III) chloride (trans-HP(DCOOH $\left.)_{2} \mathbf{F e C l}\right)$. Trans-HP(DCOOH $)_{2}(19.5 \mathrm{mg}, 18.5 \mu \mathrm{mol})$ was dissolved in $5 \mathrm{~mL}$ of DMF and added to a $10 \mathrm{~mL}$ CEM microwave tube. To this solution was added 20 equiv of $\mathrm{Fe}(\mathrm{OAc})_{2}(64.5 \mathrm{mg}, 367 \mu \mathrm{mol})$. The tube and its contents were microwaved at $75^{\circ} \mathrm{C}$ for $6 \mathrm{~h}$ with stirring and constant cooling applied. When the reaction finished, the contents of the tube were added to a separatory funnel containing $100 \mathrm{~mL}$ of EtOAc and was washed twice with $20 \% \mathrm{HCl}(\mathrm{aq})$, once with $\mathrm{DI} \mathrm{H}_{2} \mathrm{O}$, and once with brine. The organic layer was separated before being filtered through a filter paper funnel containing $20 \mathrm{~g}$ of $\mathrm{Na}_{2} \mathrm{SO}_{4}$ and rotary evaporated dry. The crude product was then taken up in minimal DCM and purified by column chromatography on the Biotage Isolera One using a $10 \mathrm{~g}$ SNAP Ultra column containing $25 \mu \mathrm{m}$ monodispersed silica (100\% DCM for 1 column volume followed by a 10-column volume gradient to $15 \% \mathrm{MeOH}$ in DCM). The lone peak detected by absorbance at $420 \mathrm{~nm}$ Visible light absorbance was then treated with $10 \mathrm{~mL}$ of $20 \% \mathrm{HCl}$ (aq) and stirred for $1 \mathrm{~h}$ before adding to a separatory funnel where the organic layer was separated off filtered through a filter paper funnel containing $20 \mathrm{~g}$ of $\mathrm{Na}_{2} \mathrm{SO}_{4}$ and rotary evaporated dry to yield the final product, which was crystallized in from THF layered with heptane. Yield $12.3 \mathrm{mg}(60 \%)$. MS (ESI): $m / z 1116.2284$ (Calcd. for [M+H] $^{+}$ 1116.2302). UV-vis (DMF): $\lambda_{\max }, \mathrm{nm} 422,505,576$.

Electrochemistry. All cyclic voltammetry (CV) experiments were conducted using a CHInstruments $760 \mathrm{C}$ potentiostat. $\mathrm{CV}$ measurements were carried out in an oven-dried custom 
glass cell (James glass) using a $3 \mathrm{~mm}$ glassy-carbon-dot working electrode (CHInstruments), platinum mesh counter electrode (BASi), and saturated calomel reference electrode (CHInstruments). Working solutions comprised $3 \mathrm{~mL}$ of electrolyte solution containing DMF with $0.1 \mathrm{M}$ tetrabutylammonium hexafluoro phosphate $\left(\left[\mathrm{TBA}^{+}\right]\left[\mathrm{PF}_{6}^{-}\right]\right), 1 \mathrm{mM} \mathrm{Fe}$ porphyrin, and varying concentration of phenol $(\mathrm{PhOH})$. The reference electrode was separated from the working solution by a double liquid junction salt-bridge (Hach) containing $10 \mathrm{~mL}$ of electrolyte solution. Working solutions were degassed with argon or carbon dioxide and kept under a positive pressure of the respective gas at all times. $\mathrm{PhOH}$ was added as a $3 \mathrm{M}$ solution to the working solution for titrations. All experiments were referenced to the ferrocenium / ferrocene couple $\left(\mathrm{Fc}^{+} / \mathrm{Fc}\right)$ by dissolution of $\sim 1.0 \mathrm{mg}$ of ferrocene into the working solution and performing a $\mathrm{CV}$ to obtain the reference potential. The working electrode was polished (Allied High Tech) after every CV with $3 \mu \mathrm{m}$ and $1 \mu \mathrm{m}$ diamond paste in ethanol (Struers), then rinsed, sonicated in ethanol to remove particulates, and rinsed with acetone before being dried under a nitrogen stream.

Bulk electrolyses were performed in a cylindrical glass cell adapted to the continuous flow detection of gases. The working compartment contained $6.0 \mathrm{~mL}$ of electrolyte solution with 500 $\mu \mathrm{M}$ Fe porphyrin and $40 \mathrm{mM}$ of $\mathrm{PhOH}$. Dissolution of compounds was facilitated by stirring solutions. The electrolyte of the counter electrode cell compartment was charged with $0.3 \mathrm{M}$ tetrabutylammonium acetate $\left(\left[\mathrm{TBA}^{+}\right]\left[\mathrm{OAc}^{-}\right]\right)$as a sacrificial reductant to facilitate current flow in the overall cell. $\mathrm{CO}_{2}$ was sparged through the working solution via a PEEK tubing at a rate of 7.3 $\mathrm{mL} \mathrm{min}^{-1}$ throughout the experiment and vented directly into the sampling loop of the gas chromatograph. The electrolyses were run for 1-2 h or until sufficient charge ( 4-5 C) had passed to ensure several catalytic turnovers. Gaseous species were identified and quantified on an SRI8610 gas chromatograph equipped with a thermal conductivity detector and flame ionization detector (multiple gas analyzer \#3, SRI Instruments). The GC was equipped with a MolSieve 5A and $2 \mathrm{~m}$ silica gel column with Argon as the carrier gas.Calibrations were made using an analytical standard containing $0.5 \% \mathrm{H}_{2}, 0.5 \% \mathrm{O}_{2}, 0.5 \% \mathrm{CO}, 0.5 \% \mathrm{CO}_{2}$ in nitrogen supplied by Sigma Aldrich (Supelco). The resultant peaks were integrated in the PeakSimple software and used as standards for further measurements. Head space samples were taken every $15 \mathrm{~min}$ to allow moderate buildup and equilibrium of gaseous products for detection. The column was maintained at $80^{\circ} \mathrm{C}$ for the first $4 \mathrm{~min}$ and heated to $250^{\circ} \mathrm{C}$ at $28^{\circ} \mathrm{C} \mathrm{min}^{-1}$ during the following $6 \mathrm{~min}$ to separate and analyze gases, followed by a 5 min cooldown period. Peaks were identified by comparison to the standards, integrated in the PeakSimple software and quantified accordingly. The only products detected in these experiments were $\mathrm{CO}$.

For each run, the $\mathrm{CO}$ peaks were integrated and then faradaic efficiency for each product gas was calculated according to,

$$
F E(A)=100\left[\frac{\frac{I n t_{\mathrm{exp}} C F_{A}}{P_{\mathrm{atm}}+P_{\mathrm{exp}}}}{\frac{(I)\left(\frac{60 s}{\min }\right)\left(\frac{1}{F}\right)\left(\frac{1}{2}\right)\left(\frac{22.4 L}{m o l}\right)}{F R}}\right]
$$




$$
C F_{A}=\frac{\left(P_{\mathrm{atm}}+P_{\text {calib }}\right)(0.005)}{I n t_{\text {calib }}}
$$

where $F E$ is faradaic efficiency, $A$ is the gaseous product being quantified $\left(\mathrm{CO}\right.$ or $\left.\mathrm{H}_{2}\right)$. Intcalib the integration of the experimental peak measured for that gas, $C F_{\mathrm{A}}$ is the calibration factor for gas $A$, calculated in eq. 3. $P_{\text {atm }}$ is the atmospheric pressure in psi $(14.7 \mathrm{psi}), P_{\exp }$ is the experimental pressure of the gas flow into the GC in psi at the time of sample collection (typically $0.02 \mathrm{PSI}$ ), $I$ is the instantaneous current in amperes, $F$ is the Faraday, $F R$ is the flow rate of $\mathrm{CO}_{2}$ through the cell at in $\mathrm{L} \mathrm{min}^{-1}$. $C F_{\mathrm{A}}$ calculated by eq. 3 , where $P_{\text {calib }}$ is the pressure of the flow for the calibration gas on sampling relative to atmospheric pressure. This pressure is multiplied by the percentage concentration of $\mathrm{CO}$ or $\mathrm{H}_{2}$ in the calibration gas $(0.005)$ and divided by Intcalib, the integration of the calibration gas peak.

Single-crystal X-ray diffraction. X-ray diffraction analysis was performed on a single crystal of HP(DCOOMe $)_{2} \mathrm{Zn}$ coated with Paratone-N oil and mounted on a MiTeGen loop. The crystal was frozen at a temperature of $100 \mathrm{~K}$ by an Oxford Cryosystems 800 Series Cryostream. Data were collected at the Harvard Department of Chemistry and Chemical Biology X-ray Laboratory on a Bruker D8 Venture diffractometer equipped with a Bruker PHOTON100 CMOS detector. Raw data were integrated and corrected for Lorentz and polarization effects using Bruker AXS SAINT software. ${ }^{4}$ Absorption corrections were applied using SADABS ${ }^{5}$ The structure was solved using intrinsic phasing using SHELXT ${ }^{6,7}$ and refined as an inversion twin (BASF $=0.422(19)$ ) using SHELXL $^{8}$ operated in the OLEX $2^{9}$ interface. No significant crystal decay was observed during data collection.

The crystal diffracted very poorly beyond $0.90 \AA$ resolution, so a resolution of $0.83 \AA$ could not be achieved. The data used for refinement was integrated to a resolution limit where intensity/sigma $>3$ and $R_{\text {int }}<0.25$. The weak diffraction of the crystal and disorder of the $\mathrm{Zn}$ porphyrin complexes lead to a structure that is of inadequate quality for accurate determination of bond distances and angles. Thus, only the overall connectivity and arrangement of molecules should be interpreted from the structure. A significant portion of the structure contains electron density that could not be modeled. This electron density is attributed to severely disordered DCM molecules that surround the $\mathrm{Zn}$ porphyrin complexes. Consequently, the unassigned electron density was accounted for using SQUEEZE ${ }^{10}$ as implemented in the PLATON interface.

For one of the two Zn porphyrin complexes in the asymmetric unit, atomic displacement restraints (RIGU and SIMU) were used to obtain a stable refinement, while for the other complex, atomic displacement parameter restraints (RIGU and SIMU), distance restraints (DFIX and SADI), as well as geometric restraints (FLAT) and constraints (AFIX) were used on the Zn complexes to obtain a stable refinement. Thermal parameters were refined anisotropically for all non-hydrogen atoms. Hydrogen atoms were placed in ideal positions.

The structure gave rise to A and B level alerts from checkCIF. Responses addressing these alerts have been included in the CIF and can be read in reports generated by checkCIF. 


\section{B. ${ }^{1} \mathrm{H}$ NMR and ${ }^{13} \mathrm{C}$ NMR Spectra}
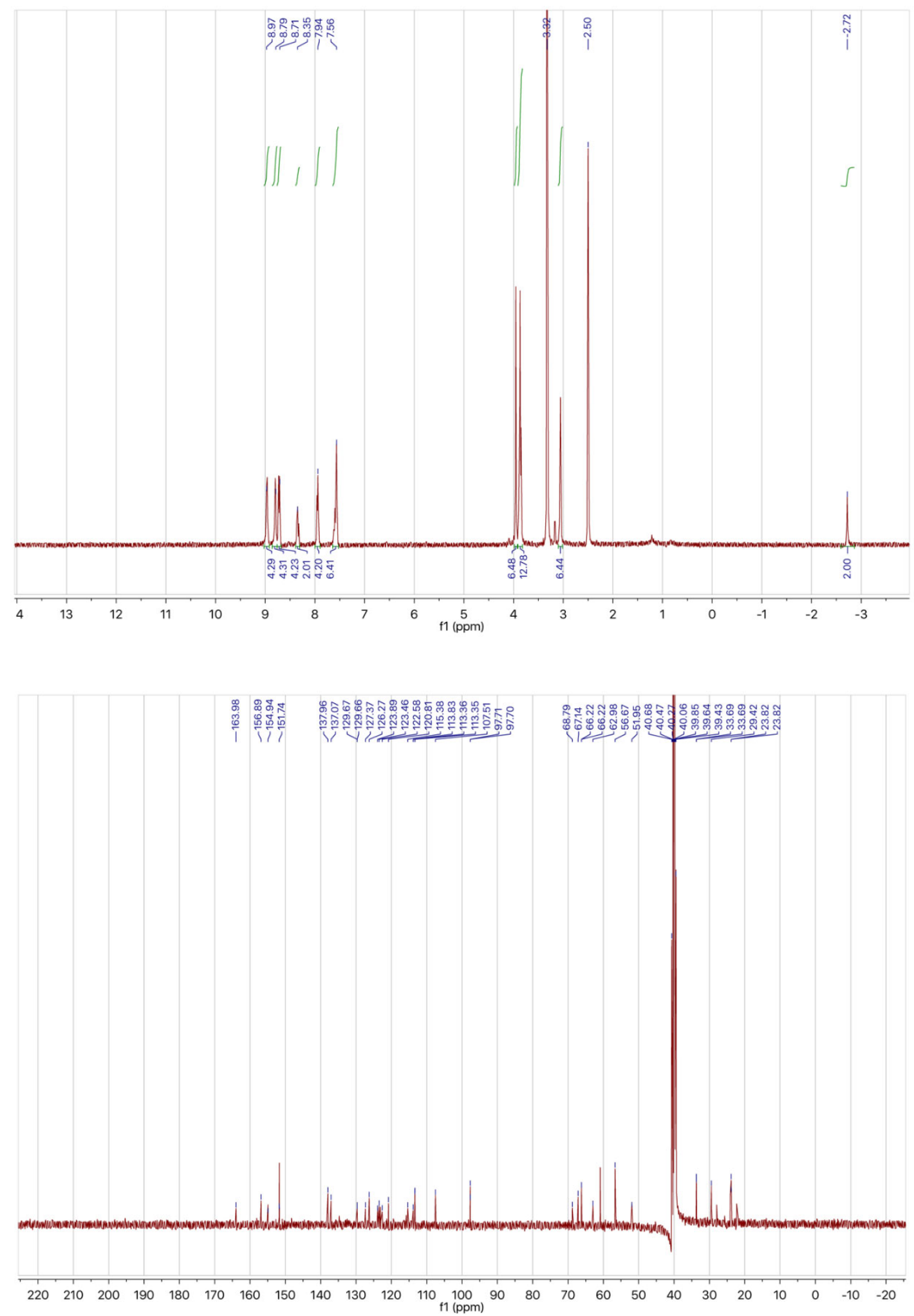

Figure S1. (top) ${ }^{1} \mathrm{H}$ NMR and (bottom) ${ }^{13} \mathrm{C}$ NMR spectra of trans-HP(DCOOMe)2. 

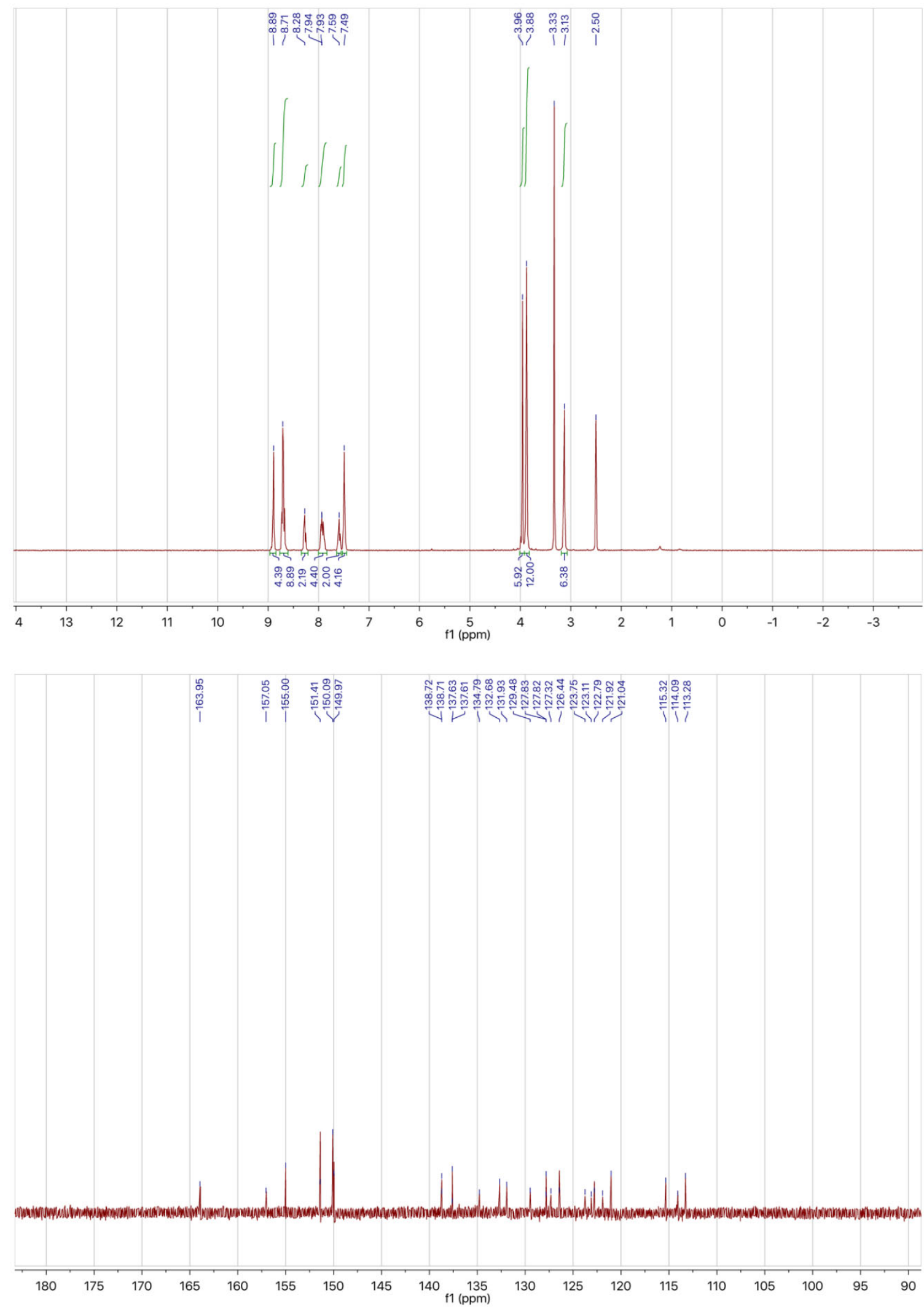

Figure S2. (top) ${ }^{1} \mathrm{H}$ and (bottom) ${ }^{13} \mathrm{C}$ NMR spectra of trans-HP(DCOOMe) $2 \mathrm{Zn}$. 

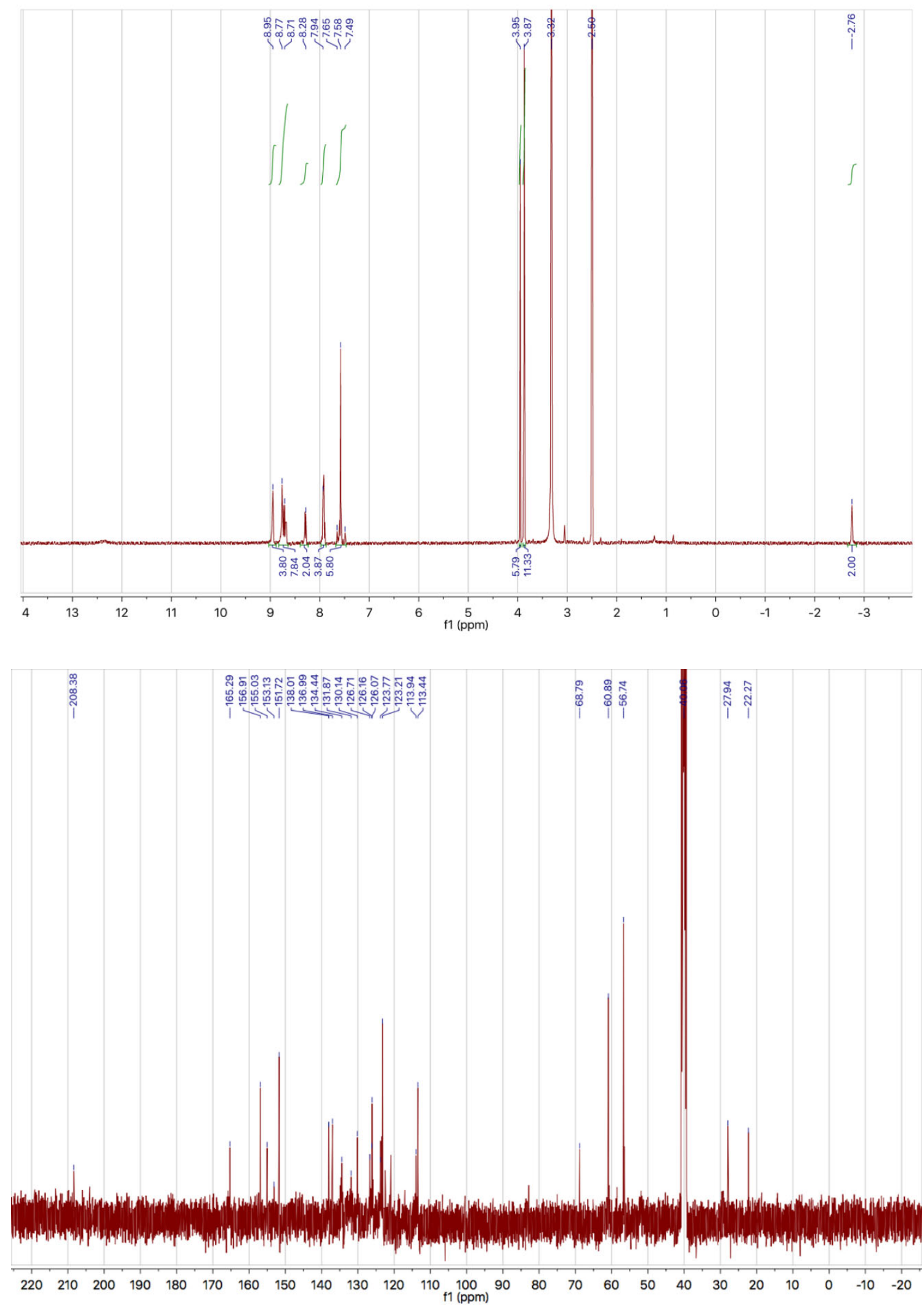

Figure S3. ${ }^{1} \mathrm{H}$ NMR and ${ }^{13} \mathrm{C}$ NMR spectra of trans-HP(DCOOH $)_{2}$. 


\section{B. Mass Spectra}

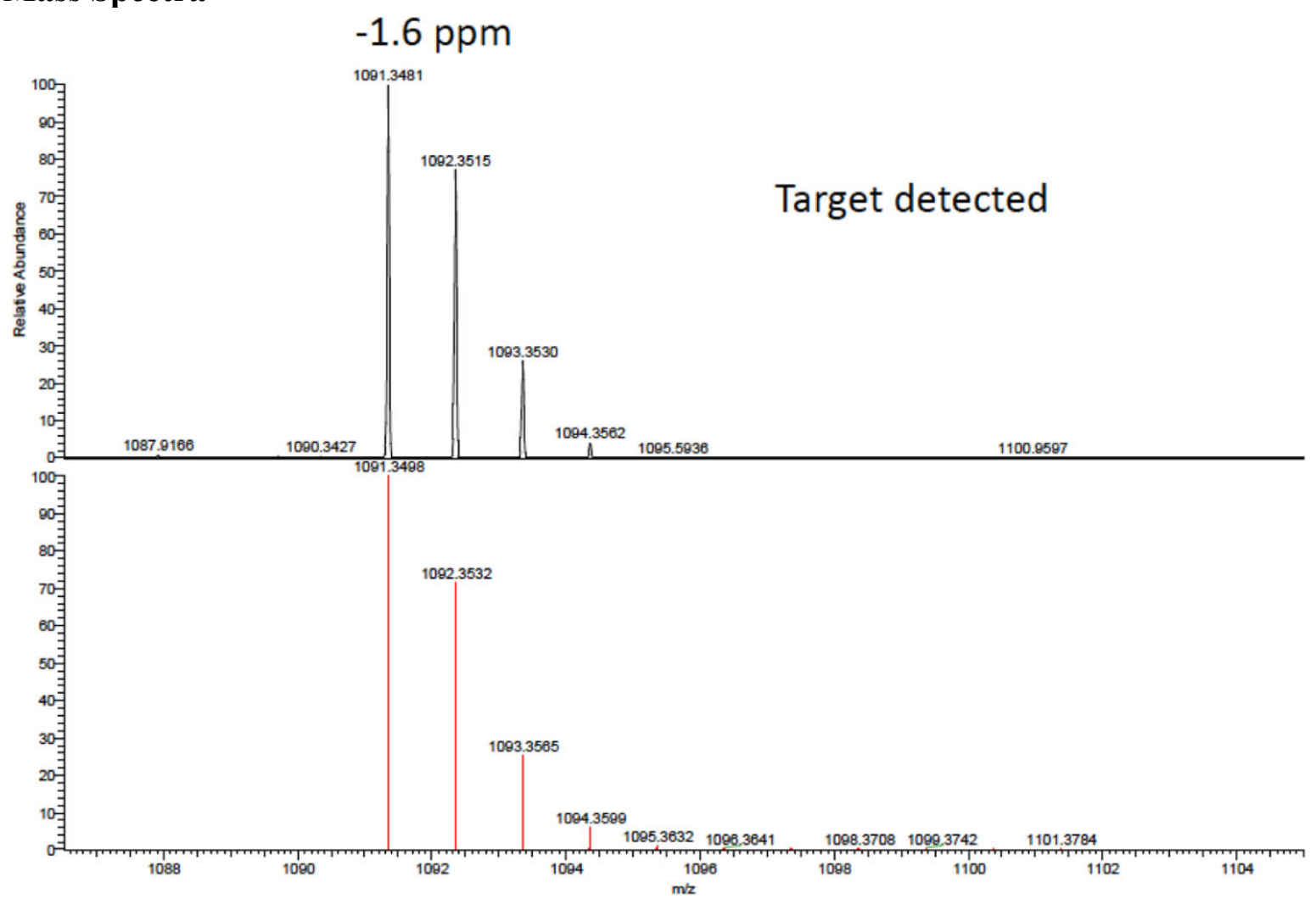

-2.2 ppm

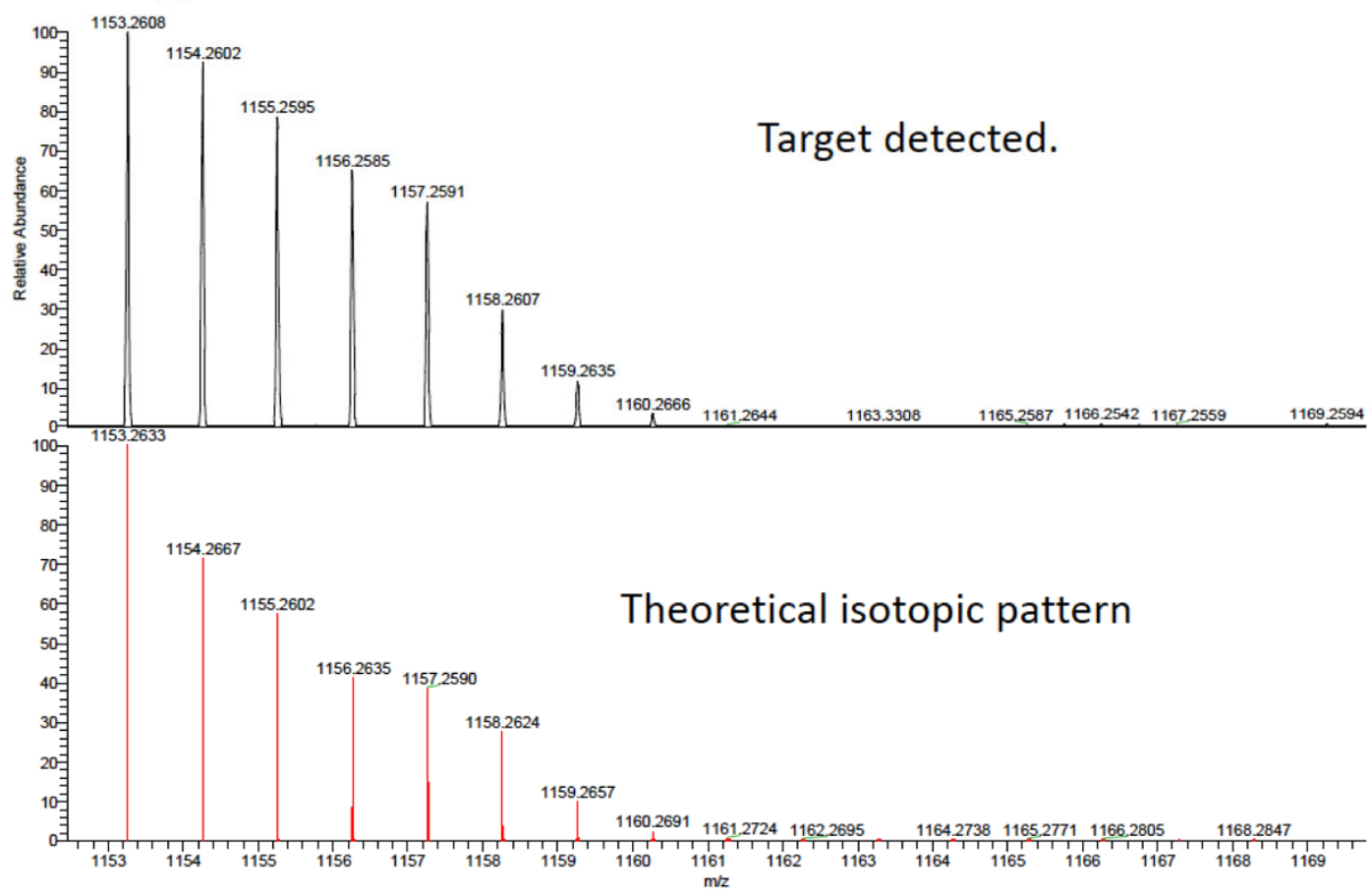

Figure S4. Mass spectrum of (top) trans-HP(DCOOMe) 2 and (bottom) trans-HP(DCOOMe) ${ }_{2} \mathrm{Zn}$. 


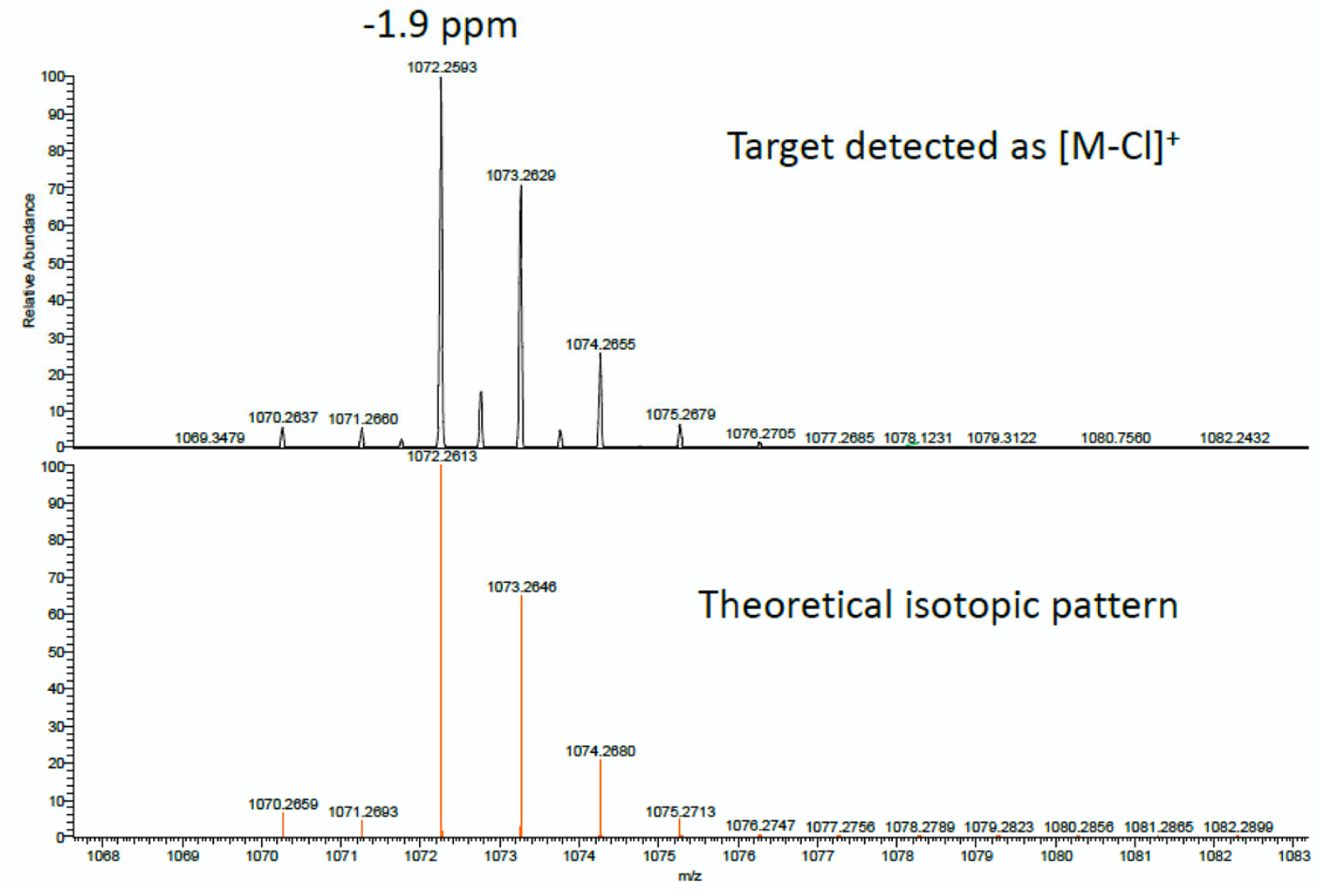

Figure S5. Mass spectrum of $\mathrm{HPD}(\mathrm{COOH}) \mathrm{FeCl}$. 

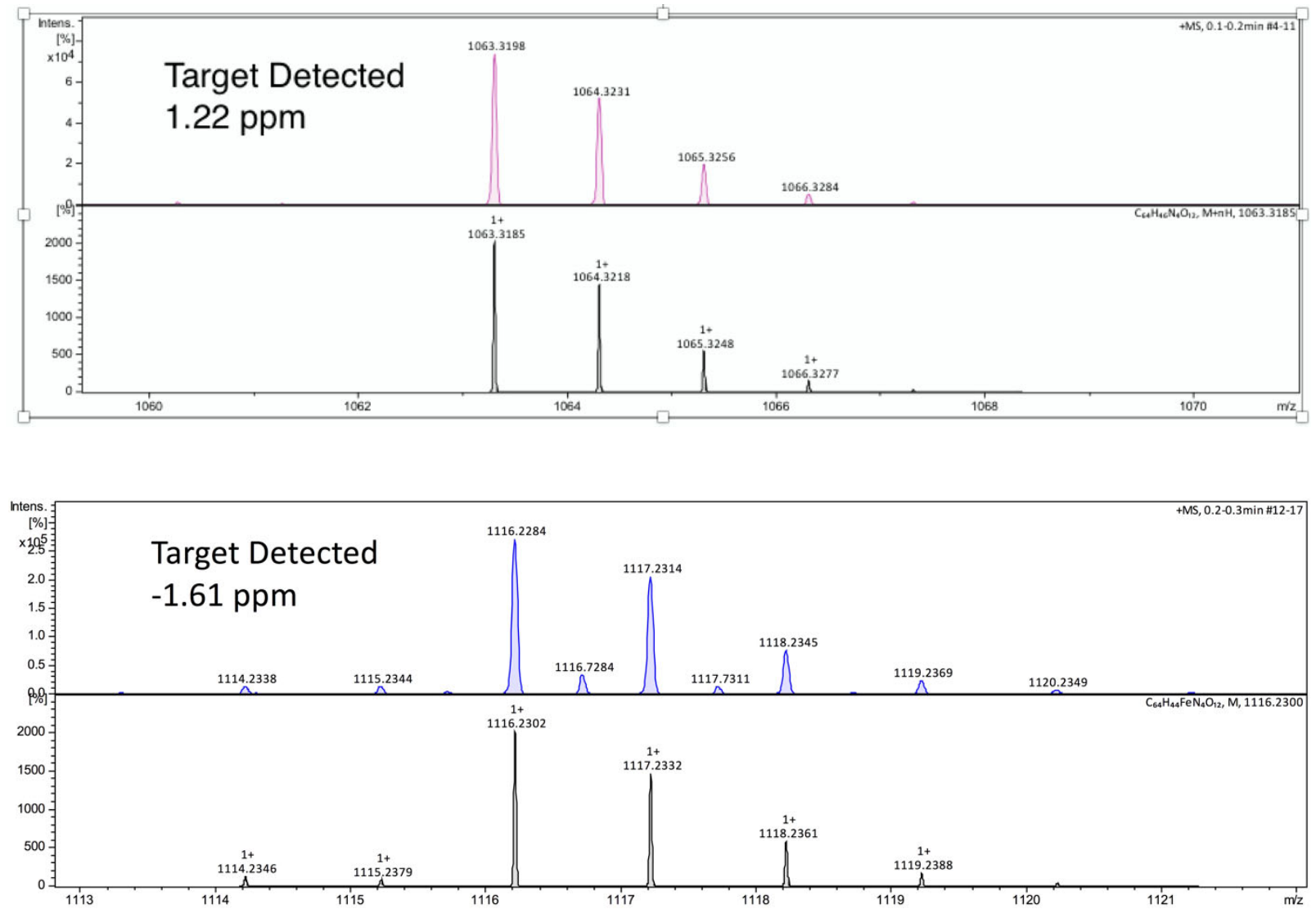

Figure S6. Mass spectrum of (top) trans-HP(DCOOH $)_{2}$ and (bottom) trans-HP(DCOOH) ${ }_{2} \mathrm{FeCl}$. 


\section{UV-Vis Spectra}
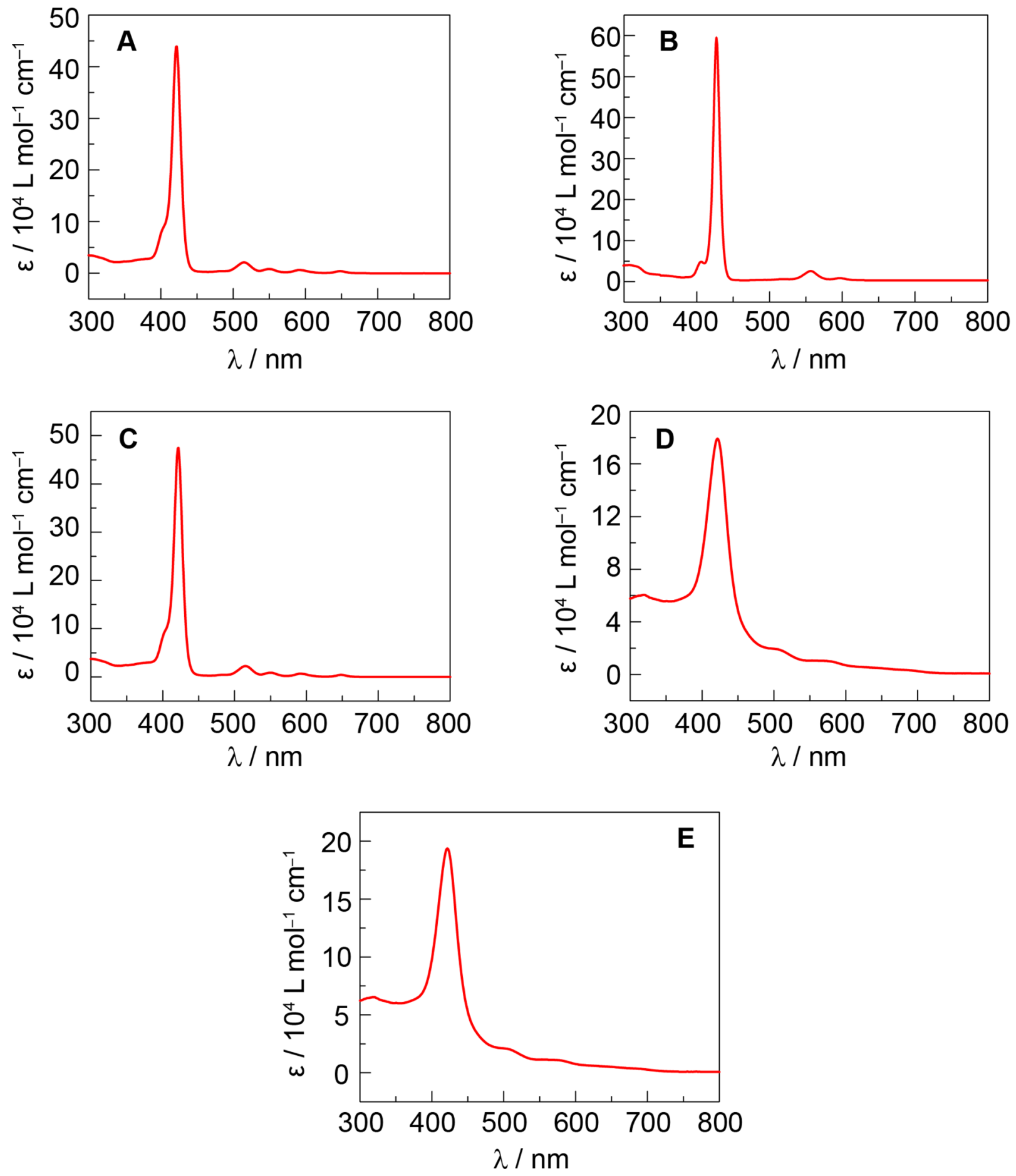

Figure S7. UV-vis spectrum of porphyrin compounds in DMF: A trans-HP(DCOOMe)2; B trans $-\mathrm{HP}(\mathrm{DCOOMe})_{2} \mathrm{Zn}$; C trans- $\mathrm{HP}(\mathrm{DCOOH})_{2} ; \mathbf{D}$ trans $-\mathrm{HP}(\mathrm{DCOOH})_{2} \mathrm{FeCl}$ and $\mathbf{E}$ $\mathrm{HPD}(\mathrm{COOH}) \mathrm{FeCl}$. 


\section{Atomic Displacement Parameters}
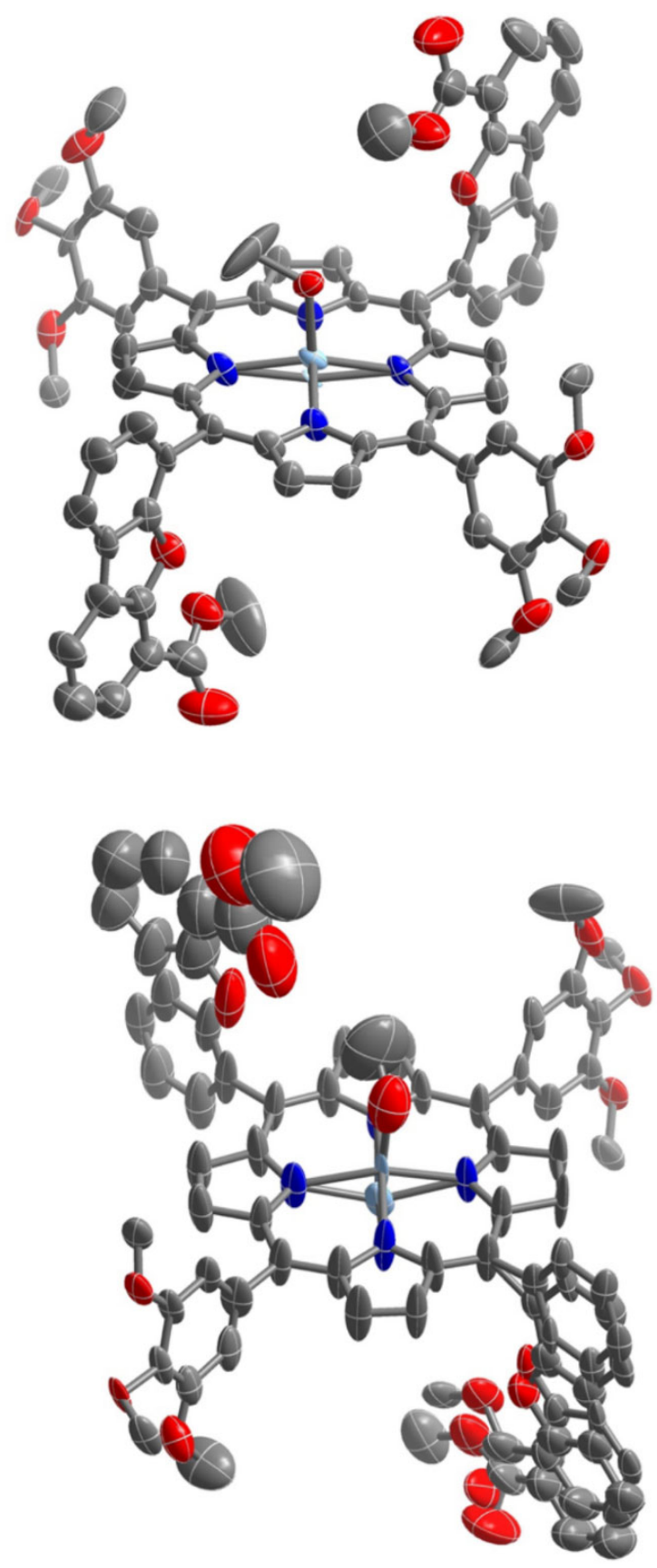

Figure S8. Atomic displacement parameter plot for the (top) first and (bottom) second of two $\mathrm{Zn}$ porphyrin complexes in the asymmetric unit in the single-crystal structure of trans$\mathrm{HP}(\mathrm{DCOOMe})_{2} \mathrm{Zn}$. A fraction of the $\mathrm{Zn}$ centers (top, 75.7(12)\%; bottom, 59.0(13)\%) were found to be square pyramidal and solvated by methanol, while the remaining $\mathrm{Zn}$ centers are pseudosquare planar. One of the dibenzofuran substituents in the second complex (bottom) was modeled to be disordered over two positions with site occupancies of $66.2(13) \%$ and $33.8(13) \%$.Hydrogen atoms are omitted for clarity. Light blue, red, blue, and grey ellipsoids represent $\mathrm{Zn}, \mathrm{O}, \mathrm{N}$, and C atoms, respectively. 
E. Table S1. Crystallographic Data of trans-HP(DCOOH $)_{2} \mathrm{Zn}$.

\begin{tabular}{|c|c|}
\hline Formula & $\mathrm{C}_{67.28} \mathrm{H}_{51.67} \mathrm{C}_{11.19} \mathrm{~N}_{4} \mathrm{O}_{12.68} \mathrm{Zn}$ \\
\hline Temperature (K) & $100(2)$ \\
\hline Crystal System & Monoclinic \\
\hline Space Group & $P 2_{1}$ \\
\hline$a, b, c(\AA)$ & $13.6905(9), 19.3639(13), 28.2678(19)$ \\
\hline$\alpha, \beta, \gamma\left(^{\circ}\right)$ & $90,97.376(2), 90$ \\
\hline$V,\left(\AA^{3}\right)$ & $7431.8(9)$ \\
\hline $\mathrm{Z}$ & 4 \\
\hline Radiation, $\lambda(\AA)$ & Mo K $\alpha, 0.71073$ \\
\hline $2 \Theta$ Range for Data Collection $\left({ }^{\circ}\right)$ & 4.358 to 46.580 \\
\hline Completeness to $2 \Theta$ & $99.6 \%\left(2 \Theta=46.580^{\circ}\right)$ \\
\hline Data / Restraints / Parameters & 20995 / 2177 / 1709 \\
\hline Goodness of Fit on $\mathrm{F}^{2}$ & 1.052 \\
\hline$R_{1}^{a}, w R_{2}^{b}(I>2 \sigma(I))$ & $0.0755,0.2128$ \\
\hline$R_{1}^{a}, w R_{2}^{b}$ (all data) & $0.0905,0.2286$ \\
\hline Largest Diff. Peak and Hole (e $\AA^{-3}$ ) & 0.756 and -0.577 \\
\hline
\end{tabular}

${ }^{a} \mathrm{R}_{1}=\sum|| \mathrm{F}_{\mathrm{o}}|-| \mathrm{F}_{\mathrm{c}}|| / \sum\left|\mathrm{F}_{\mathrm{o}}\right| \cdot{ }^{b} \mathrm{wR}_{2}=\left\{\sum\left[\mathrm{w}\left(\mathrm{F}_{\mathrm{o}}{ }^{2}-\mathrm{F}_{\mathrm{c}}{ }^{2}\right)^{2}\right] / \sum\left[\mathrm{w}\left(\mathrm{F}_{\mathrm{o}}{ }^{2}\right)^{2}\right]\right\}^{1 / 2 .}$ 


\section{F. Cyclic Voltammetry}

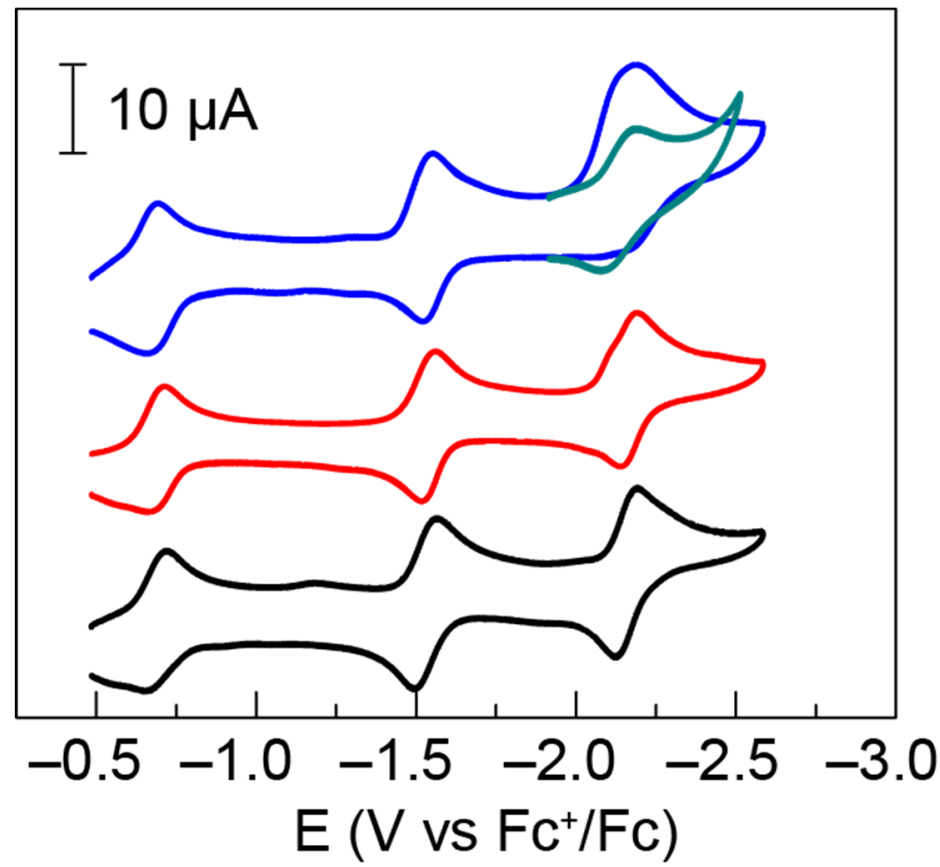

Figure S9. Cyclic voltammograms of trans- $\mathrm{HP}(\mathrm{DCOOH})_{2} \mathrm{FeCl}(-), \mathrm{HPD}(\mathrm{COOH}) \mathrm{FeCl}(-)$, $\mathrm{A}_{4}-(\mathrm{OMe})_{3} \mathrm{FeCl}(-)$ performed with a $3 \mathrm{~mm}$ glassy carbon dot electrode and $\mathrm{HP}(\mathrm{DCOOH})_{2} \mathrm{FeCl}$ $(-)$ performed with a $1 \mathrm{~mm}$ Pt dot electrode. Scans were taken at $0.1 \mathrm{~V} / \mathrm{s}$ in $0.1 \mathrm{M}\left[\mathrm{TBA}^{+}\right]\left[\mathrm{PF}_{6}{ }^{-}\right]$ in DMF under argon. 


\section{G. References}

(1) Singh, K.; Behal. S. and Hundal, M. S. Efficient and Versatile Single Pot Approach to Dipyrromethanes and Bis(heterocyclyl)methanes. Tetrahedron 2005, 61, 6614-6622.

(2) Graham, D. J.; Zheng, S.-L.; Nocera, D. G. Post-Synthetic Modification of Hangman Porphyrins Synthesized on the Gram Scale. ChemSusChem 2014, 7, 2449-2452.

(3) Graham, D. G.; Nocera, D. G. Electrocatalytic $\mathrm{H}_{2}$ Evolution by Proton-Gated Hangman Iron Porphyrins. Organometallics 2014, 33, 4994-5001.

(4) Bruker Analytical X-ray Systems, Inc. SAINT and APEX 2 Software for CCD Diffractometers; Bruker Analytical X-ray Systems, Inc.: Madison, WI, USA, 2000.

(5) Sheldrick, G. M. SADABS; Bruker Analytical X-ray Systems: Madison, WI, USA, 2014.

(6) Sheldrick, G. M. SHELXT; University of Göttingen, Germany, 2014.

(7) Sheldrick. G. M. SHELXT - Integrated Space-Group and Crystal-Structure Determination. Acta Crystallogr. A Found Adv. 2015, 71, 3-8.

(8) Sheldrick, G. M. SHELXL; University of Göttingen, Germany: University of Göttingen, Germany, 2014.

(9) Dolomanov, O. V.; Bourhis, L. J.; Gildea, R. J.; K. Howard J. A.; Puschmann, H. OLEX2: A Complete Structure Solution, Refinement and Analysis Program. J. Appl. Cryst. 2009, 42, 339-341.

(10) Spek, A. L. PLATON SQUEEZE: A Tool for the Calculation of the Disordered Solvent Contribution to the Calculated Structure Factors. Acta Cryst. 2015, 71, 9-18. 